\title{
Observations of Turbulent Heat and Momentum Fluxes during Wildland Fires in Forested Environments
}

\author{
WARREN E. HEILMAN AND XINDI BIAN \\ Northern Research Station, USDA Forest Service, Lansing, Michigan \\ KENNETH L. CLARK \\ Northern Research Station, USDA Forest Service, New Lisbon, New Jersey \\ SHIYUAN ZHONG \\ Department of Geography, Environment, and Spatial Sciences, Michigan State University, East Lansing, Michigan
}

(Manuscript received 30 July 2018, in final form 11 February 2019)

\begin{abstract}
Turbulent fluxes of heat and momentum in the vicinity of wildland fires contribute to the redistribution of heat and momentum in the fire environment, which in turn can affect the heating of fuels, fire behavior, and smoke dispersion. As an extension of previous observational studies of turbulence regimes in the vicinity of wildland fires in forested environments, this study examines the effects of spreading surface fires and forest overstory vegetation on turbulent heat and momentum fluxes from near the surface to near the top of the overstory vegetation. Profiles of high-frequency $(10 \mathrm{~Hz})$ wind velocity and temperature measurements during two prescribed fire experiments are used to assess the relative contributions of horizontal and vertical turbulent fluxes of heat and momentum to the total heat and momentum flux fields. The frequency-dependent temporal variability of the turbulent heat and momentum fluxes before, during, and after fire-front passage is also examined using cospectral analyses. The study results highlight the effects that surface wildland fires and forest overstory vegetation collectively can have on the temporal and vertical variability of turbulent heat and momentum fluxes in the vicinity of the fires and the substantial departures of heat and momentum cospectra from typical atmospheric surface-layer cospectra that can occur before, during, and after fire-front passage.
\end{abstract}

\section{Introduction}

Atmospheric turbulence regimes in the vicinity of wildland fires, which often occur in forested environments, can affect fire behavior and the dispersion of smoke (Clements et al. 2008; Mandel et al. 2009; Sun et al. 2009; Goodrick et al. 2013; Simpson et al. 2016). Fortunately, recent observational studies during wildland fire events have made great strides in improving our understanding of the evolution and properties of fire-induced atmospheric turbulence regimes. For example, Clements et al. $(2007,2008)$ conducted field experiments of wind-driven grass fires (no forest overstory present) and found that turbulent kinetic energy (TKE) generated during the fires was $4-5$ times as large as the near-surface ambient atmospheric TKE, with

Corresponding author: Dr. Warren E. Heilman, wheilman@ fs.fed.us turbulence tending to be less anisotropic within fire plumes. Observational studies of fire-atmosphere interactions and turbulence regimes during wildland fires in forested environments have also been conducted. Seto et al. $(2013,2014)$ and Heilman et al. $(2015,2017)$ conducted low-intensity prescribed fire experiments in forest ecosystems dominated by longleaf pine (Pinus palustris Mill.) and pitch pine/mixed oak (Pinus rigida Mill./Quercus spp.), respectively, and examined the velocity skewness, TKE budgets, spectral characteristics, and degree of anisotropy in the withincanopy turbulent circulations that were induced by these fires. Fire-induced turbulence in complex terrain settings (e.g., turbulent fire whirl generation during valley wind-sea breeze reversal episodes; turbulence generation during wildland fires on slopes) has been examined by Seto and Clements (2011) and Clements and Seto (2015), with those studies suggesting either buoyancy or wind shear can be the dominant mechanism for TKE generation near the fire front. 
Wildland fire field experiments associated with the Prescribed Fire Combustion and Atmospheric Dynamics Research Experiment (RxCADRE) (Ottmar et al. 2016; Clements et al. 2016) yielded new information on the potential susceptibility of low-intensity wildland fire spread to fluctuations in wind speed, with some of those changes related to ambient and fire-induced turbulence.

Two aspects of fire-induced turbulence that have received varying degrees of attention in the previously noted and other field experiment studies are the characteristics and behavior of turbulent heat fluxes and turbulent momentum fluxes (Reynolds stresses) in the vicinity of fire fronts. Turbulent heat fluxes during wildland fire events contribute to the convective heating and cooling of fuels, which are key factors, along with radiative heating, in affecting the spread of wildland fires (Dupuy and Larini 1999; Morvan and Dupuy 2004; Morandini and Silvani 2010; Frankman et al. 2013; Finney et al. 2015). Turbulent heat fluxes also redistribute heat within and near the fire environment, which affects the buoyant generation and dissipation of TKE and smoke plume behavior (Miranda 2004; Kiefer et al. 2014, 2015; Heilman et al. 2017). Turbulent momentum fluxes in the vicinity of wildland fires can bring high-momentum air from aloft and laterally into the flaming region, further affecting fire behavior (Potter 2002; Pimont et al. 2009; Nelson et al. 2012).

Because wildland fires often occur in forested environments, the turbulent fluxes of heat and momentum in the vicinity of fire fronts are influenced not only by the heating associated with the fires, but also by the overstory forest vegetation that modifies circulations associated with the ambient and fire-induced flow. Although the characteristics of turbulent heat and momentum fluxes within forest vegetation layers without any wildland fire present have been studied quite extensively (e.g., Shaw et al. 1974; Baldocchi and Meyers 1988; Amiro 1990; Raupach et al. 1996; Blanken et al. 1998; Katul et al. 1999; Patton et al. 2003; Moraes et al. 2008), few analyses of fire-affected turbulent fluxes within forest vegetation layers in the vicinity of fire fronts have been conducted. In particular, little is known about the relative importance of horizontal compared to vertical turbulent fluxes of heat and momentum near the fire environment, a factor in the convective heating of surface and overstory fuels. Also, few analyses have been conducted on the cospectral characteristics of those fluxes, which describe the contributions of different turbulent eddy sizes to the redistribution of heat and momentum through the vegetation layers.

This study builds upon and extends the previous Heilman et al. $(2015,2017)$ observational turbulence investigations by focusing on the temporal and spatial variability of observed turbulent momentum and heat fluxes within forest vegetation layers before, during, and after the passage of fire fronts typical of low-intensity backing prescribed fires employed extensively for fuels management. Assessments of horizontal and vertical fluxes near the fire environment and through the vertical extent of forest canopy layers are made, and cospectral analyses of the momentum and heat fluxes are performed to determine some of the impacts that surface heating associated with wildland fires can have on the cospectra expected for typical ambient canopy flows.

The remainder of the paper is organized as follows: A brief overview of the wildland fire field experiments and a description of the data analysis techniques that were used to support this study are found in section 2 . Section 3 a provides a short contextual summary of the general ambient and fire-induced meteorological conditions that were present during the fire experiments. Section $3 b$ presents information on how the observed horizontal and vertical turbulent heat and momentum fluxes varied from the pre-fire-front-passage (FFP) periods to the post-FFP periods at different levels within the forest canopy layers during the fire experiments, and section $3 \mathrm{c}$ presents results from cospectral analyses of the fluxes. The paper concludes in section 4 with a summary of the results and a discussion of their relevancy to predicting fire behavior and smoke dispersion during wildland fire events.

\section{Methods}

\section{a. Prescribed fire experiment field design}

Two low-intensity wildland (prescribed) fire experiments were conducted on 20 March 2011 and 6 March 2012 in the New Jersey Pinelands National Reserve to examine fire-fuel-atmosphere interactions and smoke dispersion and to generate new meteorological and airquality datasets for evaluating meteorological and airquality predictive tools applicable for simulating local wildland fire environments. The 2011 and 2012 fire experiments were conducted in 107 -ha (center of plot: $39.8726^{\circ} \mathrm{N}$, $74.5013^{\circ} \mathrm{W}$ ) and 97 -ha (center of plot: $39.9141^{\circ} \mathrm{N}$, $74.6033^{\circ} \mathrm{W}$ ) plots, respectively, containing pitch pine (Pinus rigida Mill.), Shortleaf pine (P. echinata Mill.), and mixed oak (Quercus spp.) overstory vegetation (15-23-m height) and blueberry (Vaccinium spp.), huckleberry (Gaylussacia spp.), and scrub oak understory vegetation.

Within and near each plot, below-ground, surfacebased, and tower-based (3-, 10-, 20-, and 30-m towers) soil, meteorological, and air-quality instrumentation was set up to monitor soil and atmospheric conditions [soil and air temperatures, horizontal and vertical wind velocity components, relative humidity, pressure, radiative heat fluxes, and carbon monoxide $(\mathrm{CO})$ and carbon dioxide $\left(\mathrm{CO}_{2}\right)$ 
TABLE 1. Burn-plot characteristics, ambient atmospheric and fuel conditions, line-fire properties, and fuel-consumption values for the 20 Mar 2011 and 6 Mar 2012 wildland fire experiments.

\begin{tabular}{|c|c|c|}
\hline Property & 20 Mar 2011 & 6 Mar 2012 \\
\hline \multicolumn{3}{|c|}{ Burn-plot characteristics } \\
\hline Plot size & $107 \mathrm{ha}$ & 97 ha \\
\hline Location (center of plot) & $39.8726^{\circ} \mathrm{N}, 74.5013^{\circ} \mathrm{W}$ & $39.9141^{\circ} \mathrm{N}, 74.6033^{\circ} \mathrm{W}$ \\
\hline Overstory tree heights & $18-23 \mathrm{~m}$ & $18-23 \mathrm{~m}$ \\
\hline Overstory vegetation & Pitch pine; mixed oak & Pitch/shortleaf pine; mixed oak \\
\hline Understory vegetation & Blueberry; scrub oak & Blueberry; huckleberry \\
\hline Avg understory fuel loading & $1485 \mathrm{~g} \mathrm{~m}^{-2}$ & $1104 \mathrm{~g} \mathrm{~m}^{-2}$ \\
\hline \multicolumn{3}{|c|}{ Atmospheric and fuel conditions } \\
\hline Ambient wind speed $(10 \mathrm{~m})$ & $<3 \mathrm{~m} \mathrm{~s}^{-1}$ & $<3 \mathrm{~m} \mathrm{~s}^{-1}$ \\
\hline Ambient wind direction & From NE to SE & From NW to SW \\
\hline Ambient temperature $(3 \mathrm{~m})$ & $\sim 5^{\circ}-10^{\circ} \mathrm{C}$ & $\sim 2^{\circ}-8^{\circ} \mathrm{C}$ \\
\hline Ambient relative humidity & $\sim 30 \%-60 \%$ & $\sim 20 \%-40 \%$ \\
\hline Time of initial line-fire ignition & 1355 UTC (0955 LST) & 1430 UTC (0930 LST) \\
\hline Time of FFP at $20-\mathrm{m}$ tower & 1920 UTC (1520 LST) & 2037 UTC (1537 LST) \\
\hline \multicolumn{3}{|c|}{ Line-fire properties } \\
\hline Avg line-fire spread rate & $1.50 \mathrm{~m} \mathrm{~min}^{-1}$ & $0.33 \mathrm{~m} \mathrm{~min}^{-1}$ \\
\hline Avg line-fire width & $1-2 \mathrm{~m}$ & $1-2 \mathrm{~m}$ \\
\hline Estimated fire intensity & $325 \mathrm{~kW} \mathrm{~m}^{-1}$ & $52 \mathrm{~kW} \mathrm{~m}^{-1}$ \\
\hline Avg fuel consumption & $696 \mathrm{~g} \mathrm{~m}^{-2}$ & $507 \mathrm{~g} \mathrm{~m}^{-2}$ \\
\hline
\end{tabular}

concentrations] at $10-$ or $0.5-\mathrm{Hz}$ sampling frequencies during the course of each experiment. Surface and understory fuels were destructively harvested pre- and postburn in $1 \mathrm{~m}^{2}$ plots to estimate consumption, and light detection and ranging (lidar) measurements were used to quantify canopy structure. Using drip torches, the New Jersey Forest Fire Service established downwind line fires along the western and eastern perimeters of the plots during the mornings of the 20 March 2011 and 6 March 2012 experiments, respectively (see Fig. 1 in Heilman et al. 2015). The line fires were allowed to spread against the ambient winds (i.e., backing fires) and through the instrumentation network setup within each plot. Comprehensive descriptions of the burn plots, monitoring networks, instrumentation, surface and overstory vegetation, fuel moisture, fuel loadings, burn patterns, and prescribed fire spread rates have been documented in Heilman et al. (2013, 2015, 2017) and are not repeated here. Table 1 provides a general summary of the key features and characteristics of both experiments to set the context for the analyses carried out in this paper.

\section{b. Data analyses}

As with the previous Heilman et al. $(2015,2017)$ turbulence studies of the 2011 and 2012 fires, the $10-\mathrm{Hz}$ wind velocity component and temperature measurements obtained from three-dimensional sonic anemometers and thermocouples mounted on the $20-\mathrm{m}$ towers $(3,10$, and $20 \mathrm{~m} \mathrm{AGL})$ located in the interior of the 2011 and 2012 burn plots (see Fig. 1 in Heilman et al.
2015) were used as the basis for the turbulent heat and momentum flux analyses in this study. The 20-m tower measurements provided wind and temperature data through the vertical extent of the forest overstory vegetation ( $\sim 18-\mathrm{m}$ tree heights) surrounding the $20-\mathrm{m}$ towers in the burn plots, and fire spread rates in the interior of the burn plots where the 20 -m towers were located were much less variable than near the plot boundaries. Subsequent references to the towers or the tower locations in this paper imply the $20-\mathrm{m}$ towers or 20-m tower locations, respectively. Wind velocity and temperature data were despiked and filtered to remove sporadic data values that exceeded 6 standard deviations from 1-h running means. The wind velocity component data obtained from the sonic anemometers were also tilt-corrected following the method of Wilczak et al. (2001) to minimize errors in the velocity measurements associated with anemometers not mounted exactly level.

Following the data filtering and tilt-correcting procedures, 30-min-long periods before, during, and after FFP (hereinafter referred to as pre-FFP, FFP, and postFFP periods) at the tower locations were delineated to match the 30-min-long periods used in the previous turbulence regime assessments of Heilman et al. (2015, 2017), which this study extends. For the 20 March 2011 fire experiment, the corresponding local time pre-FFP, FFP, and post-FFP periods were set at 1435-1505, 15051535, and 1535-1605 LST, respectively. For the 6 March 2012 fire experiment, the pre-FFP, FFP, and post-FFP periods were set at $1452-1522,1522-1552$, and 15521622 LST, respectively. 
Perturbation horizontal and vertical velocities $u^{\prime}, v^{\prime}$, and $w^{\prime}$ and perturbation temperatures $t^{\prime}$ during both the pre-FFP and post-FFP periods were computed every $0.1 \mathrm{~s}$ by subtracting the 30 -min block-averaged pre-FFP and post-FFP wind velocities $\bar{U}, \bar{V}$, and $\bar{W}$ and temperatures $\bar{T}$ from the despiked and filtered $10-\mathrm{Hz}$ velocity and temperature measurements $U, V, W$, and $T$ in the corresponding pre-FFP and post-FFP periods. During the defined 30-min-long FFP periods, when atmospheric circulations and temperatures at the measurement sites were strongly influenced by the fire fronts, perturbation velocities and temperatures at every $0.1 \mathrm{~s}$ were computed using the $10-\mathrm{Hz}$ FFP velocity and temperature measurements along with the pre-FFP mean velocities and temperatures. This numerical procedure, also used in the analyses of Seto et al. (2013) and Heilman et al. $(2015,2017)$, allows for a better representation of the true fire-induced circulation and temperature perturbations that characterize turbulence regimes within and near the fire environment.

Using the computed $10-\mathrm{Hz}$ perturbation velocities and temperatures for each experiment, horizontal and vertical turbulent kinematic fluxes of heat $u^{\prime} t^{\prime}, v^{\prime} t^{\prime}$, and $w^{\prime} t^{\prime}$ and momentum $u^{\prime} v^{\prime}, u^{\prime} w^{\prime}$, and $v^{\prime} w^{\prime}$ were then computed at every $0.1 \mathrm{~s}$. Hereinafter, references to heat and momentum fluxes imply their kinematic versions, as described in Stull (1988). To assess the relative importance of horizontal versus vertical turbulent heat and momentum fluxes in distributing heat and momentum within the forest overstory vegetation layers during the two fire experiments, vertical-to-total turbulent heat and momentum flux ratios $R_{\mathrm{HF}}$ and $R_{\mathrm{MF}}$, respectively, defined as

$$
\begin{aligned}
& R_{\mathrm{HF}}=\frac{\left|w^{\prime} t^{\prime}\right|}{\left[\left(u^{\prime} t^{\prime}\right)^{2}+\left(v^{\prime} t^{\prime}\right)^{2}+\left(w^{\prime} t^{\prime}\right)^{2}\right]^{1 / 2}} \quad \text { and } \\
& R_{\mathrm{MF}}=\frac{\left[\left(u^{\prime} w^{\prime}\right)^{2}+\left(v^{\prime} w^{\prime}\right)^{2}\right]^{1 / 2}}{\left[\left(u^{\prime} v^{\prime}\right)^{2}+\left(u^{\prime} w^{\prime}\right)^{2}+\left(v^{\prime} w^{\prime}\right)^{2}\right]^{1 / 2}}
\end{aligned}
$$

were computed at every $0.1 \mathrm{~s}$ within the defined 30-min-long pre-FFP, FFP, and post-FFP periods. The ratio calculations treat the instantaneous horizontal and vertical heat and momentum fluxes as vectors quantified by their absolute values, and is a simple way to quantitatively assess the relative contribution of vertical turbulent heat and momentum fluxes to the total turbulent heat and momentum flux fields at a particular location and time.

The time series of the turbulent heat and momentum fluxes at each measurement site also formed the basis for cospectral analyses of the turbulent heat and momentum fluxes during the pre-FFP, FFP, and post-FFP periods.
Because the data fields included sporadic missing values, the Lomb-Scargle periodogram technique (Scargle 1982; Press and Rybicki 1989) appropriate for generating Fourier spectra/cospectra of unevenly sampled data was utilized. The cospectral analyses of the turbulent heat and momentum fluxes during the two experiments provided the basis for assessing the temporal and spatial scales of variability of the fluxes and determining 1) how those scales of variability changed with the passage of fire fronts, 2) how the variability in horizontal fluxes of heat and momentum compared to the variability in vertical fluxes across the frequency spectrum, and 3) how wildland fires in forested environments similar to the monitored fires in this study can potentially alter the classic turbulent heat and momentum flux cospectra associated with typical surface-layer turbulence (Kaimal et al. 1972).

\section{Results and discussion}

\section{a. Observed winds and temperatures}

The observed 1-min-averaged $T$ and $U, V$, and $W$ before, during, and after FFP at the tower sites for the 20 March 2011 and 6 March 2012 fire experiments are shown in Fig. 1 (see also Fig. 3 in Heilman et al. 2017). The higher-intensity 2011 fire $\left[325 \mathrm{~kW} \mathrm{~m}^{-1}\right.$; Table 1; Byram (1959) fire-intensity formulation] relative to the 2012 fire $\left(52 \mathrm{~kW} \mathrm{~m}^{-1}\right)$ resulted in a much stronger 2011 temperature response at all levels within the forest overstory vegetation layer during the FFP period (Figs. 1a,b). Maximum 1-min-averaged temperatures at $3 \mathrm{~m}$ AGL reached $60.5^{\circ} \mathrm{C}$ at the time of FFP (1520 LST) for the 2011 experiment but only $14.4^{\circ} \mathrm{C}$ at the time of FFP (1537 LST) for the 2012 experiment. Tilting of the fire-induced convective plume during the 2011 experiment led to maximum temperatures at the 10- and 20-m levels occurring about 3 min before FFP. After FFP, substantial temperature fluctuations occurred, with temperatures dropping below ambient conditions for a short period during the 2011 experiment, particularly at the 20-m level. Temperatures returned to ambient levels $40-50 \mathrm{~min}$ after FFP. Zonal and meridional wind velocity responses to the line fire were observed in 2011 (Figs. 1c,e), but minimal responses were observed for the 2012 experiment (Figs. 1d,f). Consistent with the observed horizontal wind velocity responses, the vertical wind velocity responses in the 2011 experiment were much stronger than for the 2012 experiment (Figs. 1f,g). In 2011, 1-min-averaged vertical velocities increased to $\sim 2.5 \mathrm{~m} \mathrm{~s}^{-1}$ near the forest overstory vegetation top ( $20 \mathrm{~m} \mathrm{AGL)}$ about $3 \mathrm{~min}$ before FFP and then decreased to nearly $-1 \mathrm{~m} \mathrm{~s}^{-1}$ for a brief period following FFP. This downdraft period led to the corresponding decrease in observed temperatures below ambient temperatures noted in Fig. 1a. The vertical velocity 

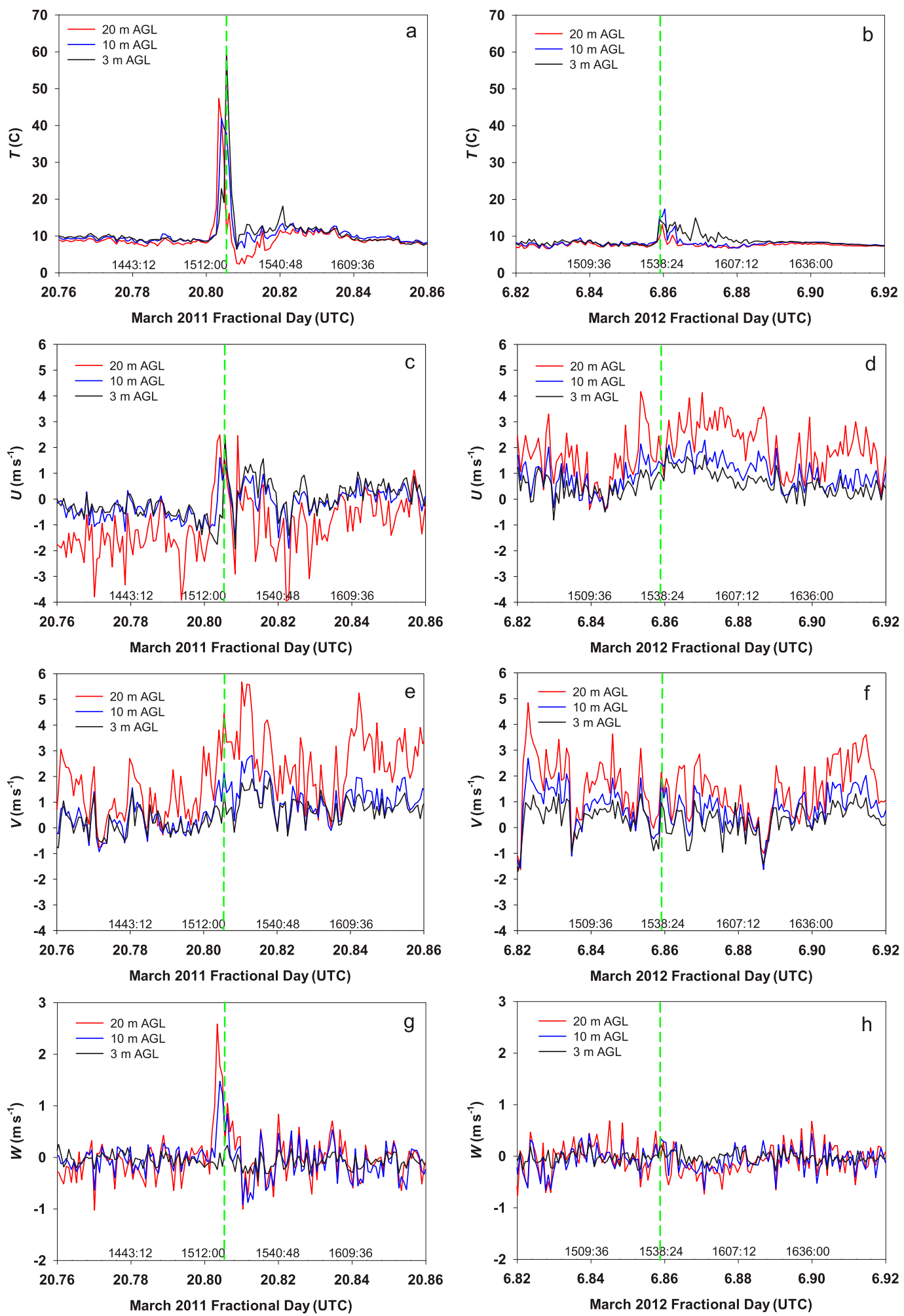

FIG. 1. Time series of observed 1-min-averaged (a),(b) temperatures $\left({ }^{\circ} \mathrm{C}\right),(\mathrm{c}),(\mathrm{d})$ zonal wind velocities $\left(\mathrm{m} \mathrm{s}^{-1}\right)$, (e),(f) meridional wind velocities $\left(\mathrm{m} \mathrm{s}^{-1}\right)$, and $(\mathrm{g}),(\mathrm{h})$ vertical wind velocities $\left(\mathrm{m} \mathrm{s}^{-1}\right)$ at 3,10 , and $20 \mathrm{~m} \mathrm{AGL} \mathrm{on} \mathrm{the}$ 20-m towers before, during, and after line fires passed the towers for the (left) 20 Mar 2011 and (right) 6 Mar 2012 fire experiments. The green vertical dashed lines indicate times of fire-front passage at the tower locations. Time stamps (hhmm:ss, where $\mathrm{hh}=$ hour, $\mathrm{mm}=$ minutes, and $\mathrm{ss}=$ seconds) in LST are shown above the lower axes. 

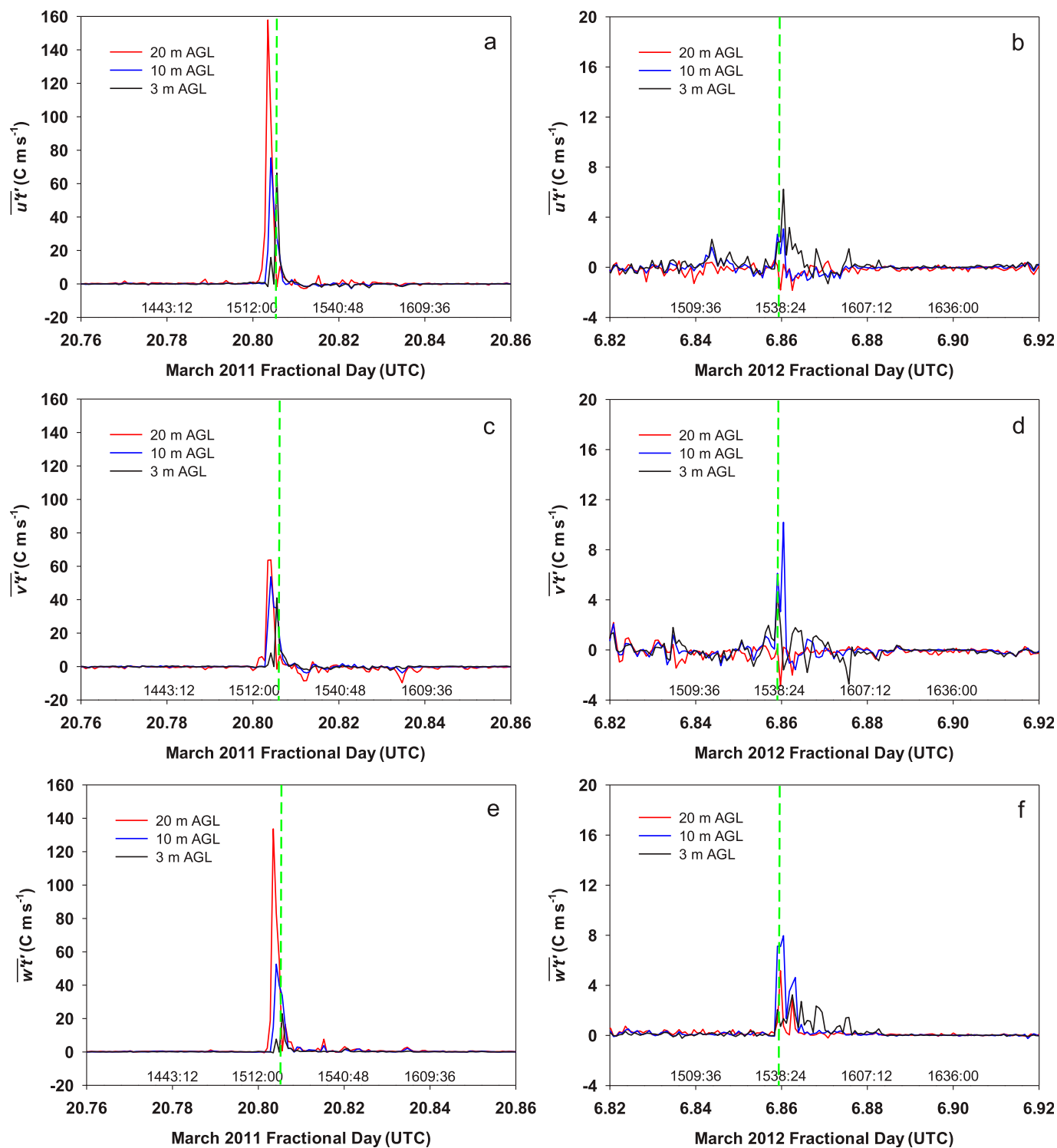

FIG. 2. Time series of observed 1-min-averaged turbulent heat fluxes $\left({ }^{\circ} \mathrm{C} \mathrm{m} \mathrm{s}^{-1}\right)$ in the (a),(b) zonal direction: $\overline{u^{\prime} t^{\prime}}$, (c),(d) meridional direction: $\overline{v^{\prime} t^{\prime}}$, and (e),(f) vertical direction: $\overline{w^{\prime} t^{\prime}}$ at 3,10 , and $20 \mathrm{~m}$ AGL on the 20 -m towers before, during, and after line fires passed the towers for the (left) 20 Mar 2011 and (right) 6 Mar 2012 fire experiments. Note the different heat flux axis scales for the 2011 and 2012 experiments. The green vertical dashed lines indicate times of fire-front passage at the tower locations. Time stamps (hhmm:ss) in LST are shown above the lower axes.

responses during the 2012 experiment were minimal. Further details related to the velocity and temperature fields observed during the 2011 and 2012 experiments can be found in Heilman et al. (2013, 2015, 2017).

\section{b. Observed turbulent heat and momentum fluxes}

Associated with the temperature and wind velocity component responses to the line fires were turbulent heat and momentum flux responses. Figure 2 shows the corresponding time series of the 1-min-averaged (overbar indicator) turbulent heat fluxes $\left(\overline{u^{\prime} t^{\prime}}, \overline{v^{\prime} t^{\prime}}\right.$, and $\left.\overline{w^{\prime} t^{\prime}}\right)$ for the two fire experiments. For the 2011 experiment, maximum values of $\overline{u^{\prime} t^{\prime}}$ and $\overline{v^{\prime} t^{\prime}}$ reached $158^{\circ} \mathrm{C} \mathrm{m} \mathrm{s}^{-1}$ and $64^{\circ} \mathrm{C} \mathrm{m} \mathrm{s}^{-1}$, respectively, about $3 \mathrm{~min}$ before the time of FFP (1520 LST) at the 20-m level (Figs. 2a,c). A maximum vertical heat flux $\overline{w^{\prime} t^{\prime}}$ of $134^{\circ} \mathrm{C} \mathrm{m} \mathrm{s}^{-1}$ was also observed at the 20-m level at that time (Fig. 2e). Lower maximum turbulent heat flux values were observed near the surface ( $3 \mathrm{~m} \mathrm{AGL}$ ) and at the midcanopy level (10 $\mathrm{m}$ AGL). For the lower-intensity 2012 fire experiment, 
turbulent heat flux values close to the time of FFP were much lower, and maximum values during and after FFP were found at the 3- or 10-m levels instead of near the canopy top (Figs. 2b,d,f). Before and after FFP for both experiments, average turbulent heat flux absolute values were generally less than $1^{\circ}-3^{\circ} \mathrm{C} \mathrm{m} \mathrm{s}^{-1}$, although the flux variations during the post-FFP periods were somewhat larger than during the pre-FFP periods. Regardless of the fire intensity, though, there were many occurrences of horizontal turbulent heat flux magnitudes exceeding the vertical turbulent heat flux magnitudes during the highly buoyant FFP periods.

A closer examination of the relative importance of horizontal versus vertical turbulent heat fluxes in distributing heat within the forest overstory vegetation layers during these two fire experiments is highlighted in Fig. 3. Here, individual 5-min averages of the $10-\mathrm{Hz}$ heat flux ratios $R_{\mathrm{HF}}$ [see Eq. (1)] were computed within the defined 30-min-long pre-FFP, FFP, and post-FFP periods. For the 2011 experiment (Fig. 3a), the 5-minaveraged ratios were almost always less than 0.5 throughout the pre-FFP, FFP, and post-FFP periods, and they were generally larger at midcanopy levels than near the surface or canopy top. The smallest ratio $\left(R_{\mathrm{HF}}=0.18\right)$, in fact, occurred during the latter stages of the highly buoyant FFP period at the 3-m level. Similar mean ratio values were observed during the lower-intensity 2012 experiment (Fig. 3b); all mean ratios were between 0.2 and 0.5 before, during, and after FFP. However, variations in the mean ratios from the 3-m level up to the 20-m level were smaller in 2012 than in 2011.

While the time series of the 5-min-averaged heat flux ratios shown in Fig. 3 suggest modest variations in ratio values over the 90 -min pre-FFP to post-FFP periods, a Kruskal-Wallis one-way analysis of variance (ANOVA) on ranks (appropriate for assessing nonnormal distributions) indicates that the differences in median ratio values between the pre-FFP and FFP periods at all height levels for both fire experiments were statistically significant $(p<0.001)$ (Table 2). For both experiments, the median (and mean) heat flux ratios during the FFP periods were always less than those during the pre-FFP period throughout the vertical extent of the forest overstory vegetation layer. Median heat flux ratio values during the post-FFP periods also were almost always less than the pre-FFP median values, but the differences were smaller than the differences between the FFP and pre-FFP periods. However, all the pre-FFP and postFFP median heat flux ratio differences were still statistically significant except for the differences at the 10- and 20-m levels for the 2011 experiment.

For the momentum flux fields, the 1-min-averaged turbulent momentum fluxes shown in Fig. 4 suggest
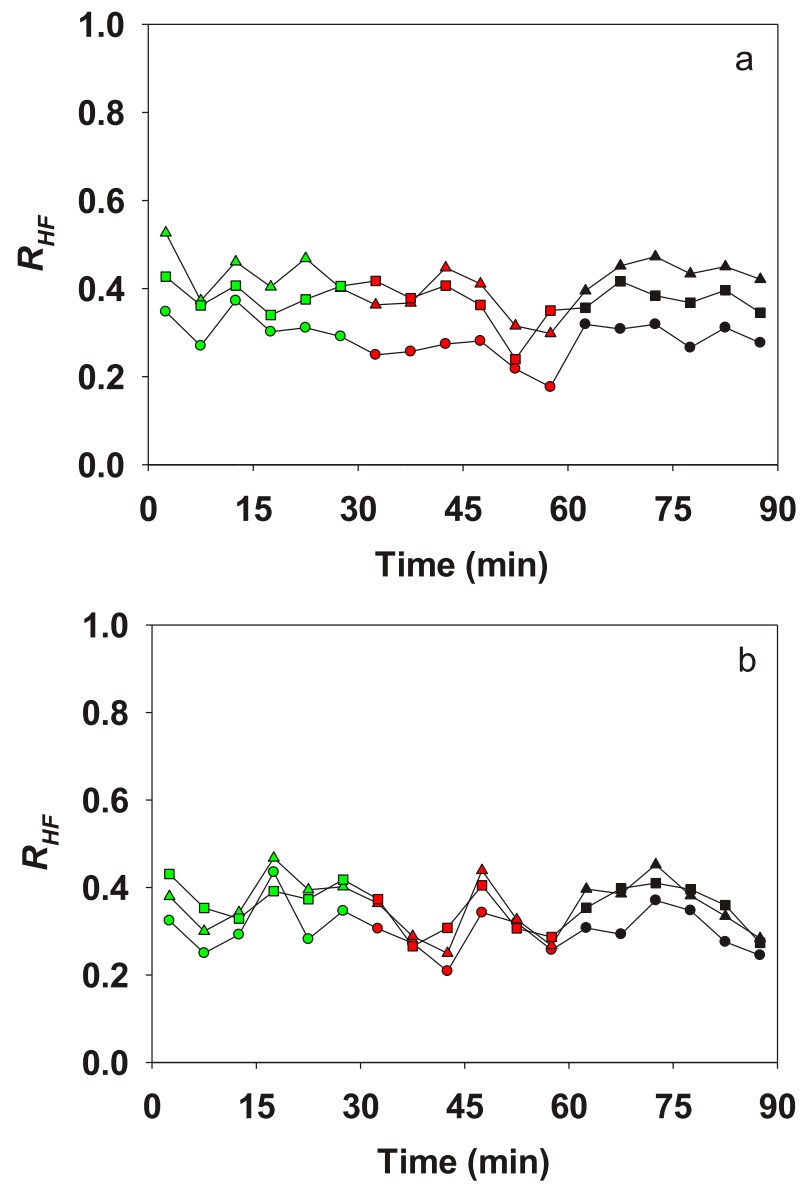

FIG. 3. Time series of the ratios of 5-min-averaged vertical to total turbulent heat flux $R_{\mathrm{HF}}$ at 3 (circles), 10 (triangles), and 20 (squares) $\mathrm{m}$ AGL during the 90-min period centered on the time of FFP at the 20-m tower locations for the (a) 20 Mar 2011 and (b) 6 Mar 2012 fire experiments. The green, red, and black symbols indicate 5-min averages during the defined 30-min-long pre-FFP, FFP, and post-FFP periods, respectively, for each experiment.

magnitudes of momentum fluxes in the horizontal direction can also exceed magnitude fluxes in the vertical direction within the fire environment. During the 2011 experiment, values of $\overline{u^{\prime} v^{\prime}}$ greater than 12 and less than $-5 \mathrm{~m}^{2} \mathrm{~s}^{-2}$ were observed close to the time of FFP and during the post-FFP period at the 20-m level (Fig. 4a). Maximum and minimum values of the 1-minaveraged vertical turbulent momentum fluxes $\overline{u^{\prime} w^{\prime}}$ and $\overline{v^{\prime} w^{\prime}}$ were 10.5 (Fig. 4c) and -4.9 (Fig. 4e) $\mathrm{m}^{2} \mathrm{~s}^{-2}$, respectively, again at the $20-\mathrm{m}$ level. The variability in $\overline{u^{\prime} v^{\prime}}$ values, particularly during and following FFP, was also greater than the variability observed in the $\overline{u^{\prime} w^{\prime}}$ and $\overline{v^{\prime} w^{\prime}}$ vertical momentum fluxes. The 1-min-averaged turbulent momentum flux responses to the lower-intensity fire in 2012 were minimal (Figs. 4b,d,f), unlike the 2012 turbulent heat flux responses that were conspicuous, albeit small, near the time of FFP (Figs. 2b,d,f). 
TABLE 2. Mean and median turbulent heat flux ratios $R_{\mathrm{HF}}$ and turbulent momentum flux ratios $R_{\mathrm{MF}}$ during defined 30-min-long preFFP, FFP, and post-FFP periods at three height levels on the 20-m towers for the 20 Mar 2011 and 6 Mar 2012 wildland fire experiments. Time intervals are shown in LST. Median ratio values during the FFP or post-FFP periods that have statistically significant variations $(p<$ 0.001) from the pre-FFP period are shown in boldface type.

\begin{tabular}{|c|c|c|c|c|c|c|c|}
\hline \multirow[b]{2}{*}{ Height (m) } & \multirow[b]{2}{*}{ Quantity } & \multicolumn{3}{|c|}{20 Mar 2011} & \multicolumn{3}{|c|}{6 Mar 2012} \\
\hline & & $\begin{array}{c}\text { Pre-FFP } \\
(1435-1505)\end{array}$ & $\begin{array}{c}\text { FFP } \\
(1505-1535)\end{array}$ & $\begin{array}{c}\text { Post-FFP } \\
(1535-1605)\end{array}$ & $\begin{array}{c}\text { Pre-FFP } \\
(1452-1522)\end{array}$ & $\begin{array}{c}\text { FFP } \\
1522-1552\end{array}$ & $\begin{array}{c}\text { Post-FFP } \\
1552-1622\end{array}$ \\
\hline \multirow[t]{4}{*}{20} & $R_{\mathrm{HF}}:$ Mean & 0.386 & 0.359 & 0.378 & 0.382 & 0.324 & 0.365 \\
\hline & $R_{\mathrm{HF}}:$ Median & 0.350 & 0.318 & 0.350 & 0.337 & 0.277 & 0.333 \\
\hline & $R_{\mathrm{MF}}:$ Mean & 0.684 & 0.648 & 0.690 & 0.698 & 0.642 & 0.682 \\
\hline & $R_{\mathrm{MF}}:$ Median & 0.753 & 0.725 & 0.760 & 0.787 & 0.702 & 0.773 \\
\hline \multirow[t]{4}{*}{10} & $R_{\mathrm{HF}}:$ Mean & 0.439 & 0.367 & 0.437 & 0.381 & 0.322 & 0.372 \\
\hline & $R_{\mathrm{HF}}:$ Median & 0.434 & 0.332 & 0.429 & 0.351 & 0.267 & 0.334 \\
\hline & $R_{\mathrm{MF}}:$ Mean & 0.724 & 0.656 & 0.734 & 0.698 & 0.604 & 0.686 \\
\hline & $R_{\mathrm{MF}}:$ Median & 0.835 & 0.726 & 0.836 & 0.791 & 0.646 & 0.778 \\
\hline \multirow[t]{4}{*}{3} & $R_{\mathrm{HF}}:$ Mean & 0.316 & 0.243 & 0.300 & 0.322 & 0.284 & 0.306 \\
\hline & $R_{\mathrm{HF}}:$ Median & 0.270 & 0.182 & 0.243 & 0.273 & 0.228 & 0.248 \\
\hline & $R_{\mathrm{MF}}:$ Mean & 0.635 & 0.523 & 0.597 & 0.617 & 0.578 & 0.615 \\
\hline & $R_{\mathrm{MF}}:$ Median & 0.704 & 0.518 & 0.649 & 0.675 & 0.605 & 0.671 \\
\hline
\end{tabular}

Using the momentum flux ratio $R_{\mathrm{MF}}$ computation shown in Eq. (2), a quantitative assessment of the relative contribution of vertical turbulent momentum fluxes to the total turbulent momentum flux field during the preFFP, FFP, and post-FFP periods was carried out (Fig. 5). The 5-min-averaged momentum flux ratios for the 2011 experiment, shown in Fig. 5a, varied from 0.44 (FFP period at the 3-m level) to 0.79 (pre-FFP period at the $10-\mathrm{m}$ level). Like the mean heat flux ratios in 2011, the mean momentum flux ratios were generally larger at the midcanopy (10-m level) than near the canopy top or surface. In 2012, the momentum flux ratio variations from the 3-m level to the 20-m level and from the pre-FFP period to the post-FFP period were smaller (Fig. 5b), consistent with the 2012 heat flux ratio variations.

At all levels within the forest overstory vegetation layer, the passage of the fire fronts in both experiments led to statistically significant reductions in the median momentum flux ratio values from the pre-FFP periods to the FFP periods (Kruskal-Wallis ANOVA on ranks test appropriate for nonnormal distributions), similar to what was observed for the median heat flux ratios (Table 2). This suggests that the relative contribution of the horizontal turbulent flux of momentum to the total momentum flux field can be enhanced during FFP periods. During the post-FFP periods, median momentum flux ratio values increased from their FFP values at all levels, but were still significantly lower than their corresponding pre-FFP values at the 3-m level during the 2011 experiment and at the 20 -m level during the 2012 experiment $(p<0.001)$.

\section{c. Turbulent heat and momentum flux cospectra}

The spatial and temporal variations observed in the turbulent heat and momentum fluxes during the
2011 and 2012 fire experiments were manifestations of ambient and fire-induced fluctuations in the temperature and the horizontal and vertical velocity fields. The fluctuations occurred over a wide range of frequencies associated with turbulent eddies of different sizes.

Figure 6 shows the frequency-weighted, vertical turbulent heat flux $w^{\prime} t^{\prime}$ cospectra at the tower locations before, during, and after FFP for the 2011 and 2012 fire experiments. A number of features in the cospectra patterns are consistent between the 2011 and 2012 fires. First, as expected, the FFP periods resulted in substantially higher cospectral power values than the preFFP and post-FFP values, particularly for the 2011 fire (Figs. 6a,c,e). Second, the post-FFP cospectra power values almost always fell between the pre-FFP and FFP values. The exception occurred at the 20-m level during the 2012 experiment (Fig. 6b), which is consistent with the vertical velocity spectra associated with the turbulent circulations before, during, and after FFP for the 2011 and 2012 fires (see Fig. 4 in Heilman et al. (2015)). Third, over the higher-frequency inertial subrange portions of the cospectra, the slopes of the turbulent heat flux cospectral curves departed from the $-4 / 3$ slope expected for typical surface-layer turbulence fields (Kaimal et al. 1972) and observed by Amiro (1990) in boreal forest canopies. During the pre-FFP and postFFP periods, the slope values of the cospectral curves in the inertial subrange were closer to $-2 / 3$, the approximate inertial subrange slope value observed for both the horizontal and vertical velocity spectral curves for the 2011 and 2012 fires, as reported in Heilman et al. (2015). The most substantial departures occurred during the FFP periods, with cospectral power values remaining 

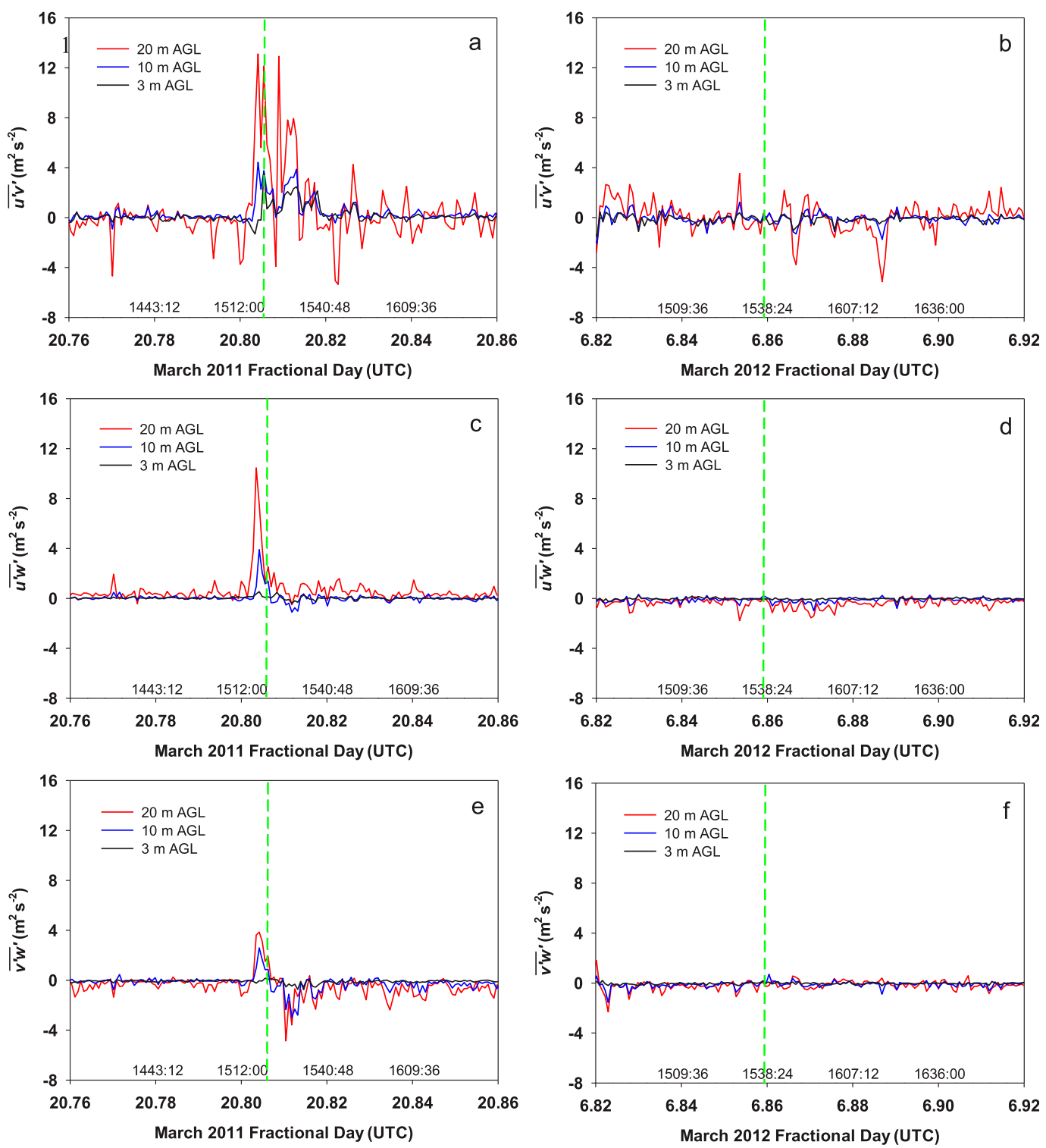

FIG. 4. Time series of observed 1-min-averaged turbulent momentum fluxes $\left(\mathrm{m}^{2} \mathrm{~s}^{-2}\right.$ ): (a), (b) $\overline{u^{\prime} v^{\prime}}$, (c), (d) $\overline{u^{\prime} w^{\prime}}$, and (e),(f) $\overline{v^{\prime} w^{\prime}}$ at 3, 10, and $20 \mathrm{~m}$ AGL on the 20-m towers before, during, and after line fires passed the towers for the (left) 20 Mar 2011 and (right) 6 Mar 2012 fire experiments. The green vertical dashed lines indicate times of firefront passage at the tower locations. Time stamps (hhmm:ss) in LST are shown above the lower axes.

fairly flat or increasing slightly with increasing frequency, as shown in Fig. 6e for the 3-m level during the 2011 experiment. The flat or slightly increasing cospectral power value trends in the inertial subrange during FFP periods are consistent with the vertical velocity and temperature spectral slope behavior reported by Seto et al. (2013) for a similar type of subcanopy fire experiment conducted in a longleaf pine forest. This suggests that coherent high-frequency vertical velocity and temperature fluctuations during FFP periods may be equally important as lower-frequency fluctuations in governing the turbulent vertical mixing of heat, especially near the surface in forested environments.

The cospectral curves for the horizontal turbulent heat fluxes $u^{\prime} t^{\prime}$ and $v^{\prime} t^{\prime}$ (not shown) exhibited similar characteristics to the vertical turbulent heat flux cospectral curves, including behavior in the inertial subrange portion of the frequency spectrum. Cospectra power values during the FFP periods were substantially higher than during the pre-FFP periods, and power values during the post-FFP periods usually fell between the pre-FFP and FFP associated values. The exception was at the 10- and 

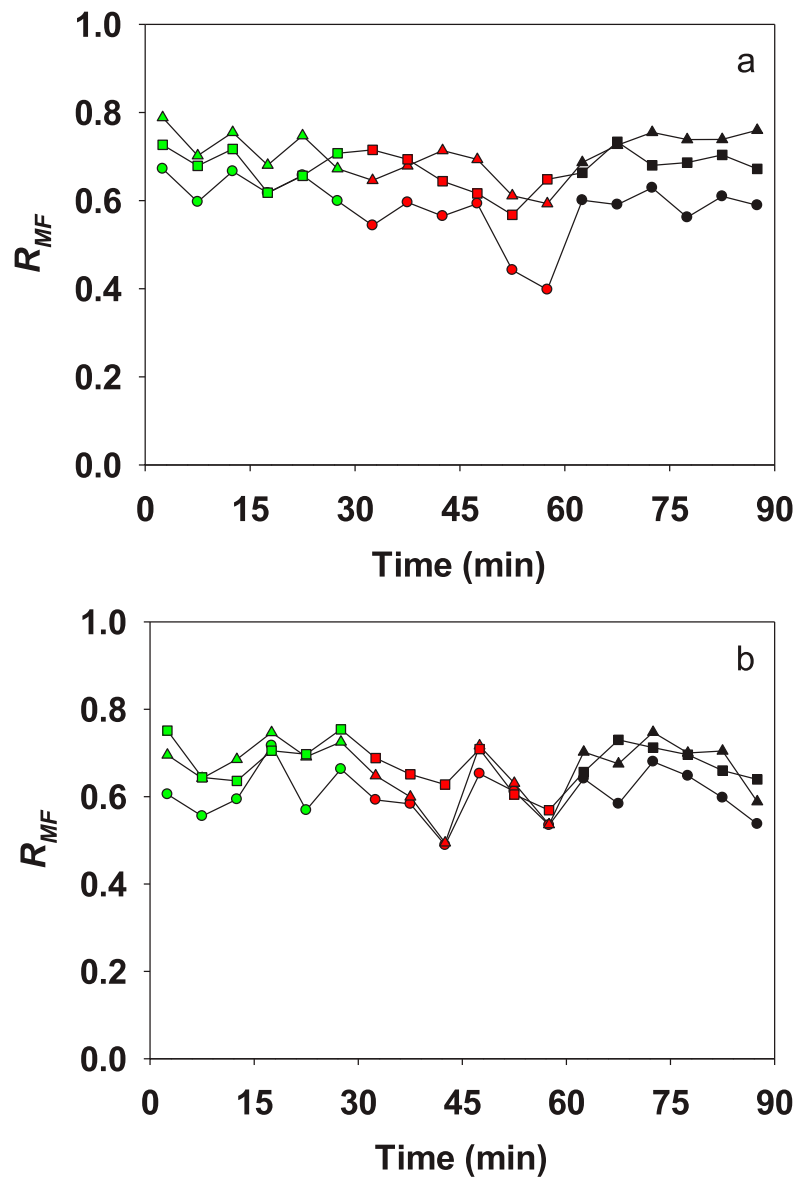

FIG. 5. As in Fig. 3, but for turbulent momentum flux ratios $R_{\mathrm{MF}}$.

20-m levels during the 2012 experiment, when post-FFP power values fell below the pre-FFP power values.

A graphical summary of how the vertical and horizontal turbulent heat flux cospectra power values compared to each other across the frequency spectrum is shown in Fig. 7. During pre-FFP periods, vertical turbulent heat flux variability was much less than horizontal turbulent heat flux variability across the entire frequency spectrum, with vertical to horizontal cospectra power ratios less than 0.5 at all height levels for both experiments. There was a slight increase in the preFFP ratio values as the frequency increased. During FFP periods, fluctuations in the vertical turbulent heat flux increased relative to fluctuations in the horizontal heat flux, resulting in higher FFP ratio values relative to the pre-FFP values. The highest FFP ratios during the 2011 experiment were observed near the canopy top $(20 \mathrm{~m}$ AGL), where values exceeded 1 within the $0.05-0.1$ and $0.1-1.0 \mathrm{~s}^{-1}$ frequency intervals (Fig. 7a). During the lower-intensity 2012 fire experiment, FFP ratios greater than 1 were very common at the 20- and $10-\mathrm{m}$ levels (Figs. $7 b, d$ ). The post-FFP period ratios exceeded the
pre-FFP and FFP ratios within every frequency interval at the 3-m level for both fire experiments, and those ratios generally increased with increasing frequency (Figs. 7e,f). Very large post-FFP ratios relative to the pre-FFP and FFP ratios characterized the $10-\mathrm{m}$ level during the lower-intensity 2012 experiment, with a maximum ratio value exceeding 5 within the $0.05-0.1 \mathrm{~s}^{-1}$ frequency interval (Fig. 7d).

The turbulent momentum flux cospectra for the 2011 and 2012 fire experiments, like the heat flux cospectra, reveal how surface fires in forested environments can alter the surface-layer momentum flux cospectra from what one would expect under no-fire conditions. Figure 8 shows the frequency-weighted, vertical momentum flux $u^{\prime} w^{\prime}$ cospectra at the tower locations before, during, and after FFP for the 2011 and 2012 fire experiments. For the 2011 fire experiment, Figs. 8a, 8c, and 8e show cospectra patterns in the pre-FFP, FFP, and post-FFP periods consistent with the vertical heat flux cospectra patterns shown in Figs. 6a, 6c, and 6e, although the departures of the FFP momentum flux cospectra curves from the preFFP and post-FFP curves were substantially less than the departures shown in the temperature-perturbationdependent heat flux cospectra. Cospectra power values were smallest during the pre-FFP period, while the postFFP cospectra power values usually fell between the preFFP and FFP values. Inertial subrange cospectra power values during the FFP period did not decrease with increasing frequency; slope values of the FFP cospectra curves were closer to 0 than the Kaimal et al. (1972) suggested $-4 / 3$ slope value in the inertial subrange. The inertial subrange pre-FFP and post-FFP cospectra curve slopes also departed from the $-4 / 3$ value, with values closer to $-2 / 3$. The less steep slope values are consistent with the findings of Amiro (1990) in his analysis of vertical momentum flux cospectra within boreal forest canopies; slope values close to -1 were reported in that study. The lower-intensity 2012 fire had a much smaller impact on the turbulent vertical momentum flux $u^{\prime} w^{\prime}$ cospectra than the 2011 fire (Figs. 8b,d,f). At the 20- and $10-\mathrm{m}$ levels, variations among the cospectra curves from the pre-FFP period through the FFP period and into the post-FFP period were small (Figs. 8b,d). At the 3-m level, the increase in FFP cospectra power values over the pre-FFP and post-FFP values within the inertial subrange was slightly more substantial (Fig. 8f). Slope values for the cospectra curves in the inertial subrange, regardless of height or fire period, were close to $-2 / 3$.

Cospectra for the horizontal turbulent momentum flux $u^{\prime} v^{\prime}$ (not shown) and vertical turbulent momentum flux $v^{\prime} w^{\prime}$ (not shown) had similar features to the $u^{\prime} w^{\prime}$ cospectra with respect to relative differences in cospectra power 

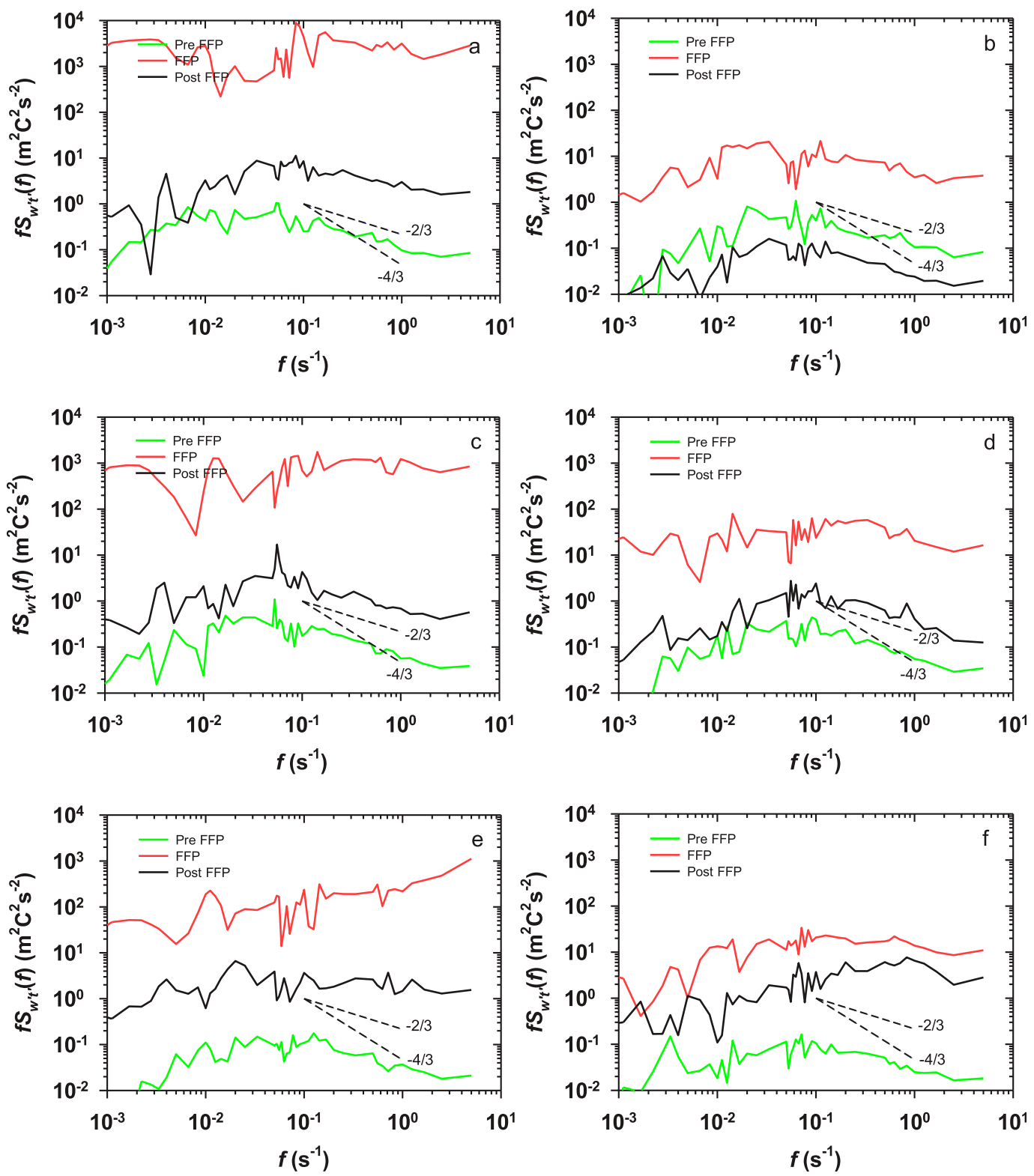

FIG. 6. Frequency-weighted turbulent heat flux cospectra $f S_{w^{\prime} t^{\prime}}(f)\left(\mathrm{m}^{2}{ }^{\circ} \mathrm{C}^{2} \mathrm{~s}^{-2}\right)$ as a function of frequency $f\left(\mathrm{~s}^{-1}\right)$ at (a),(b) 20, (c),(d) 10, and (e),(f) $3 \mathrm{~m}$ AGL on the 20-m towers during the pre-FFP, FFP, and post-FFP periods for the (left) 20 Mar 2011 and (right) 6 Mar 2012 fire experiments. The dashed lines represent the $-2 / 3$ and $-4 / 3$ inertial subrange slopes of the vertical velocity spectral curves and vertical turbulent heat flux cospectral curves, respectively, as suggested by the Kolmogorov (1941) theory and the surface-layer observations reported in Kaimal et al. (1972).

values between the pre-FFP, FFP, and post-FFP periods for the 2011 and 2012 experiments. However, maximum $u^{\prime} v^{\prime}$ cospectra power values at the different height levels and during the different fire periods generally occurred at lower frequencies $\left(\sim 0.01 \mathrm{~s}^{-1}\right)$ than for the maximum $u^{\prime} w^{\prime}$ and $v^{\prime} w^{\prime}$ cospectra power values $\left(\sim 0.1 \mathrm{~s}^{-1}\right)$. This is consistent with the observed lower frequencies at which maximum horizontal velocity spectral power values occurred compared to the frequencies of maximum vertical velocity spectral power values for the two experiments, as reported in Heilman et al. (2015). The tendency for fluctuations in the horizontal momentum flux to exceed the fluctuations in the vertical momentum flux at lower frequencies (longer fluctuation periods) is reflected in the turbulent momentum flux cospectra ratios shown in Fig. 9. Average ratios of the vertical to 


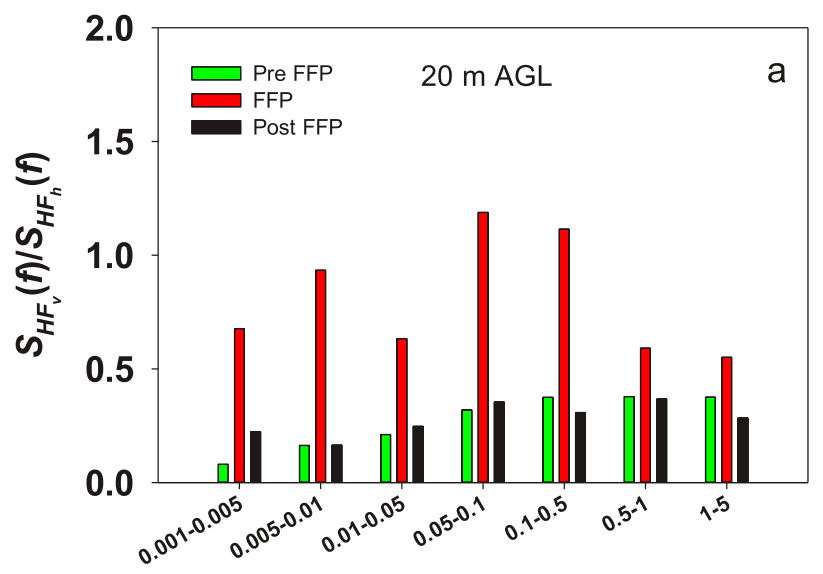

Binned $f\left(s^{-1}\right)$

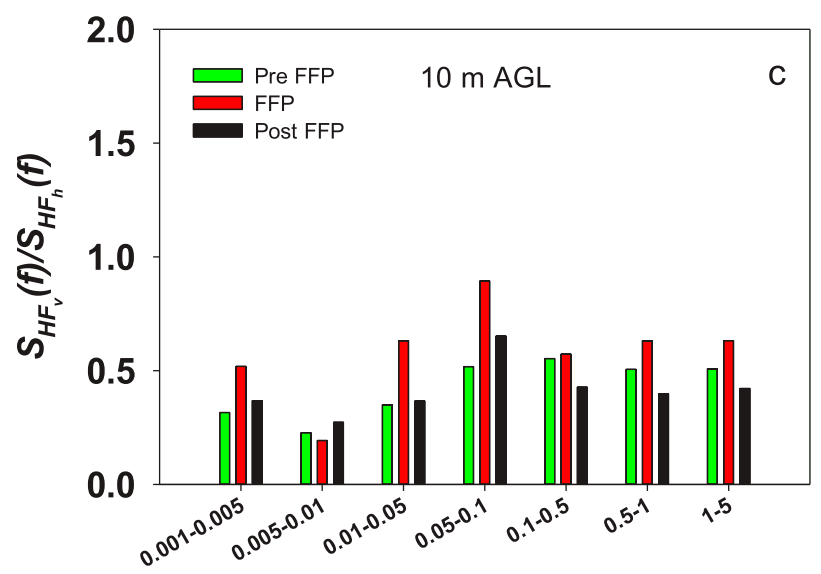

Binned $f\left(\mathbf{s}^{-1}\right)$

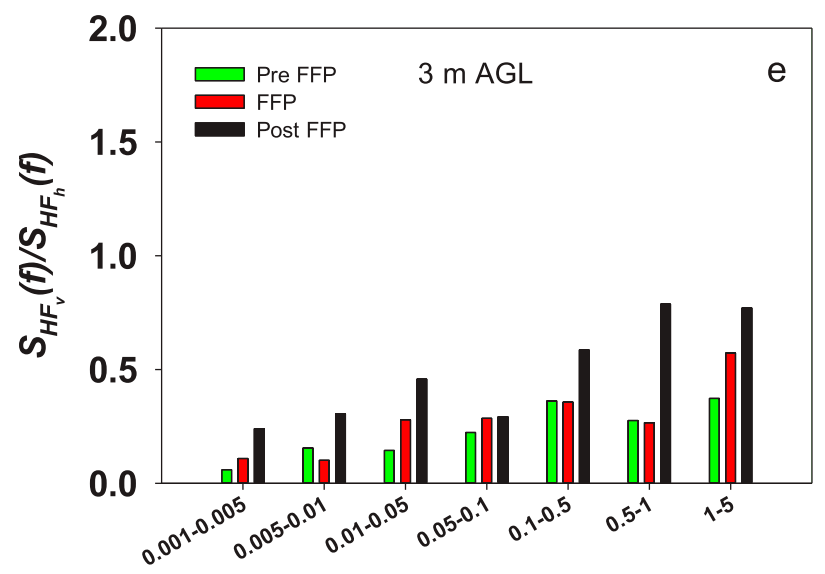

Binned $f\left(s^{-1}\right)$

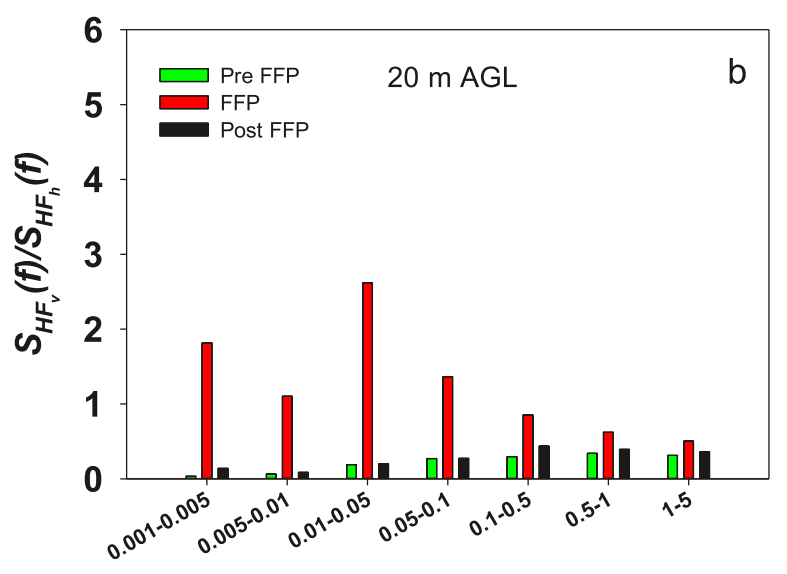

Binned $f\left(\mathbf{s}^{-1}\right)$

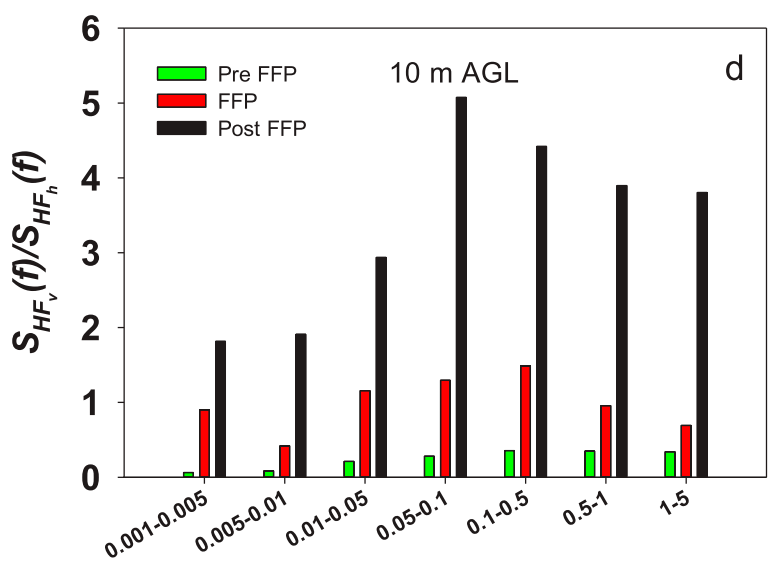

Binned $f\left(s^{-1}\right)$

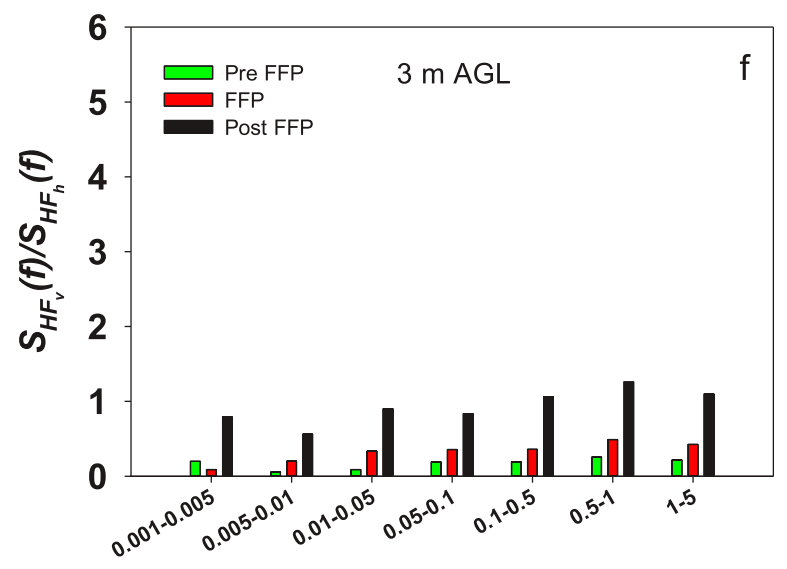

Binned $f\left(\mathrm{~s}^{-1}\right)$

FIG. 7. Average ratios within different frequency $f\left(\mathrm{~s}^{-1}\right)$ bins of the vertical turbulent heat flux cospectra power $S_{\mathrm{HF}_{v}}(f)$ to the horizontal turbulent heat flux cospectra power $S_{\mathrm{HF}_{h}}(f)$ at (a),(b) 20, (c),(d) 10, and (e),(f) $3 \mathrm{~m}$ AGL on the 20-m towers during the pre-FFP, FFP, and post-FFP periods for the (left) 20 Mar 2011 and (right) 6 Mar 2012 fire experiments. Note the different cospectra power ratio axis scales for the 2011 and 2012 experiments. 

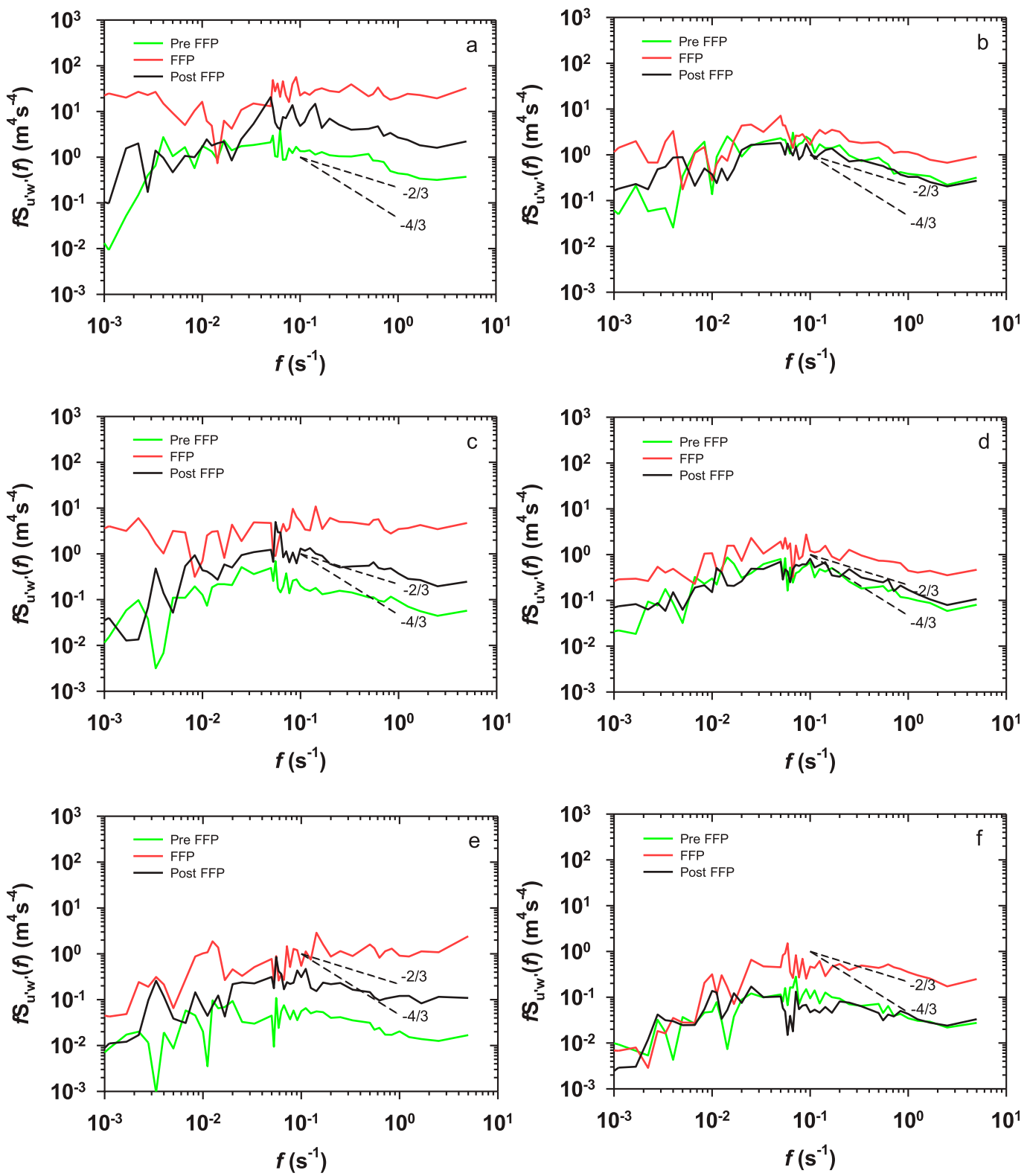

FIG. 8. As in Fig. 6, but for frequency-weighted turbulent momentum flux cospectra $f S_{u^{\prime} w^{\prime}}(f)\left(\mathrm{m}^{4} \mathrm{~s}^{-4}\right)$.

horizontal momentum flux cospectra values were less than 0.5 at frequencies less than $0.1 \mathrm{~s}^{-1}$ at the 3 - and 20-m levels during the pre-FFP, FFP, and post-FFP periods (Figs. 9a,b,e,f). At the 10-m midcanopy level, average ratios over the lower-frequency portion of the spectrum were larger during the different periods but still less than 1 (Figs. 9c,d). At frequencies greater than $0.1 \mathrm{~s}^{-1}$, average ratios almost always exceeded 0.5 and sometimes exceeded 1 . Unlike the turbulent heat flux cospectra ratios (Fig. 7), substantial ratio differences between the pre-FFP, FFP, and post-FFP periods were less conspicuous across the entire frequency spectrum.

\section{Summary and conclusions}

Building upon the previous analyses of turbulence regimes in the vicinity of wildland fires conducted by Heilman et al. (2015, 2017), this study focused on the characteristics of vertical and horizontal turbulent heat and momentum fluxes near the fire fronts of backing surface fires within forest vegetation layers. Highfrequency $(10 \mathrm{~Hz})$ atmospheric circulation and temperature measurements at three heights during two prescribed fire experiments conducted in the New Jersey Pine Barrens on 20 March 2011 and 6 March 2012 formed the 


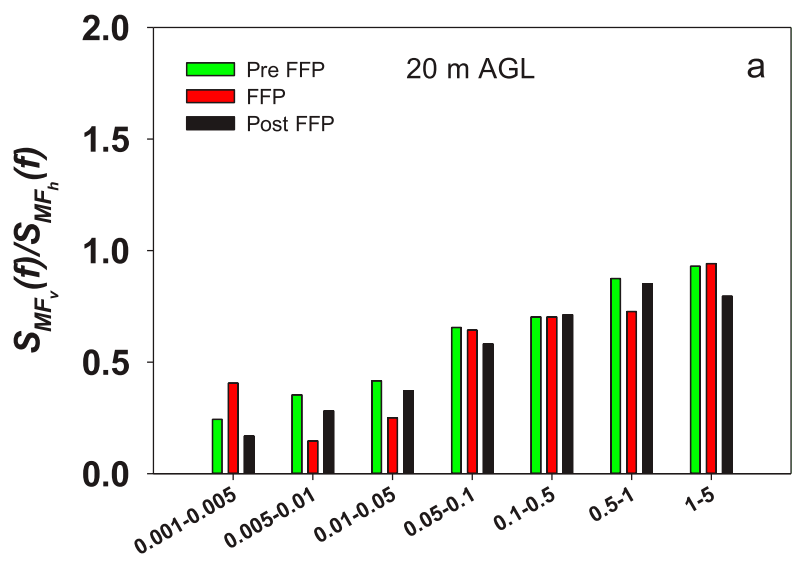

Binned $f\left(s^{-1}\right)$

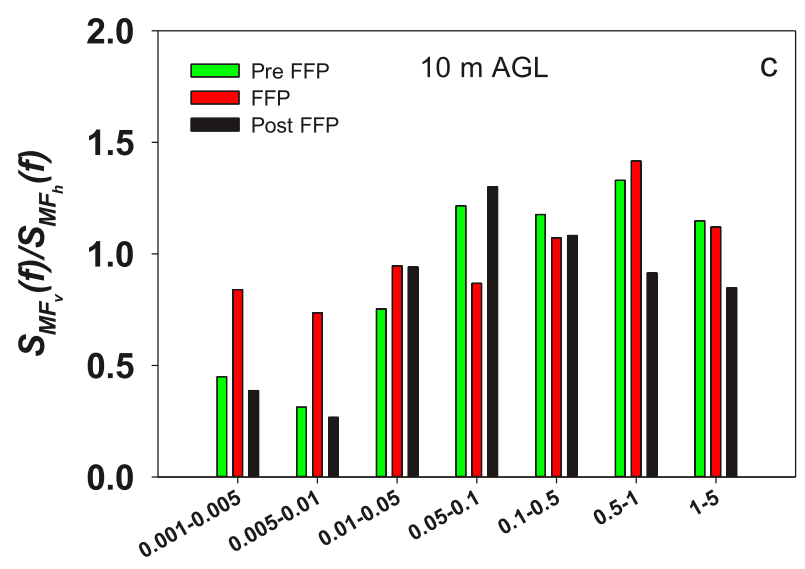

Binned $f\left(s^{-1}\right)$

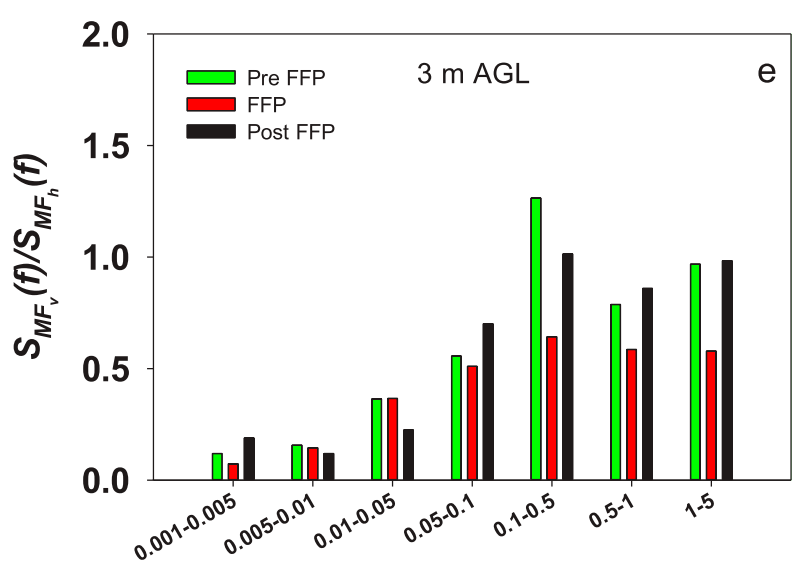

Binned $f\left(\mathrm{~s}^{-1}\right)$
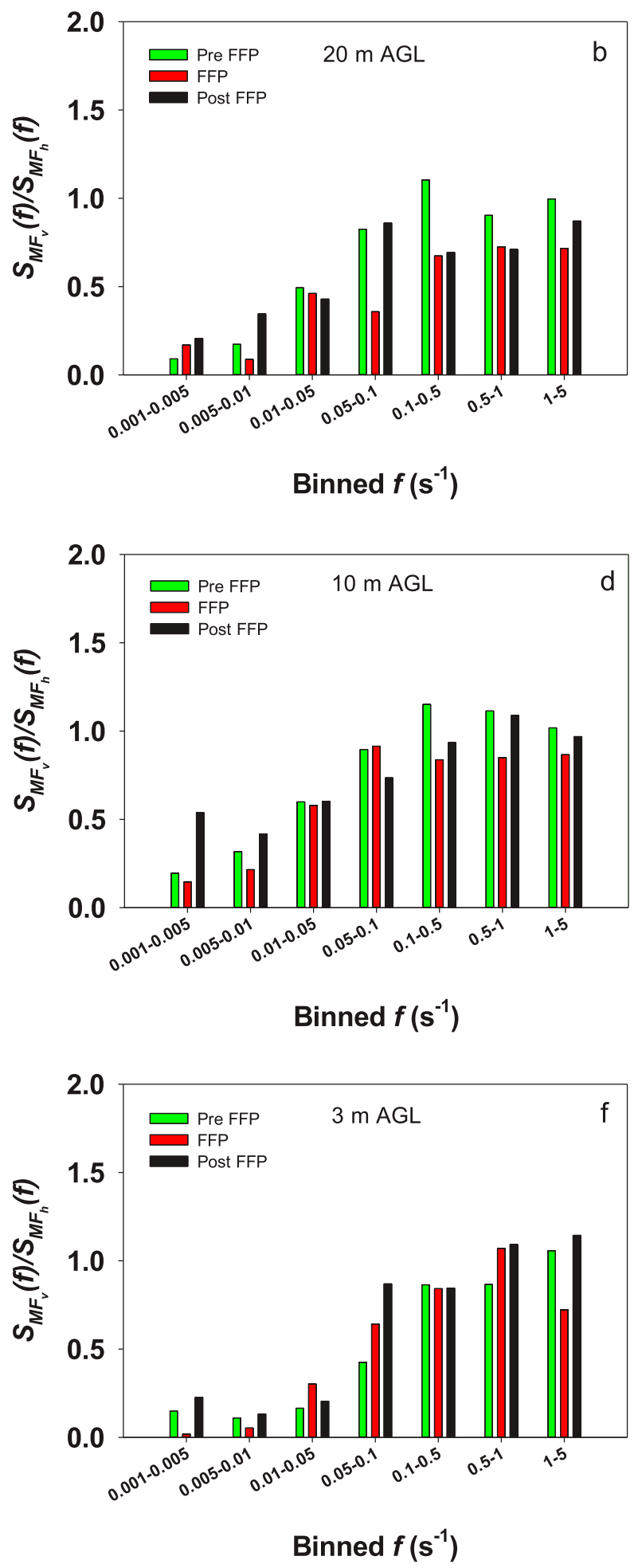

FIG. 9. As in Fig. 7, but for the ratio of the vertical turbulent momentum flux cospectra power $S_{\mathrm{MF}_{v}}(f)$ to the horizontal turbulent momentum flux cospectra power $S_{\mathrm{MF}_{h}}(f)$. 
basis for computing high-frequency turbulent heat and momentum fluxes and assessing their spatial and temporal variability in the vicinity of the line fires in each experiment.

The surface line fires induced significant temperature and wind velocity component perturbations in the vicinity of the fire fronts. Maximum 1-min-averaged temperature perturbations of $\sim 50^{\circ}$ and $10^{\circ} \mathrm{C}$ at $3 \mathrm{~m} \mathrm{AGL}$ were observed at the time of FFP for the higher-intensity 2011 fire and the lower-intensity 2012 fire, respectively. Perturbations in the horizontal and vertical wind velocity components were also prevalent close to the time of FFP during both experiments, with maximum perturbations $\left(\sim 2-4 \mathrm{~ms}^{-1}\right)$ occurring near the top of the overstory vegetation (20m AGL) during the 2011 experiment. Following FFP, temperature and velocity component perturbations gradually diminished, with temperatures and velocities returning to ambient values within minutes.

Associated with the temperature and wind velocity component perturbations that occurred in response to the line fires were horizontal and vertical turbulent heat and momentum fluxes. Maximum 1-min-averaged horizontal heat and momentum flux magnitudes during FFP periods were found to be as large as or larger than the maximum vertical flux magnitudes. The largest heat and momentum flux magnitudes usually occurred near the canopy top. On average, vertical turbulent heat fluxes were found to contribute about $20 \%-50 \%$ to the total turbulent heat flux field from the pre-FFP period to the post-FFP period, while vertical turbulent momentum fluxes contributed about $40 \%-80 \%$ to the total turbulent momentum flux field. Vertical turbulent heat and momentum fluxes tended to contribute more to the total turbulent heat and momentum flux fields at the midcanopy level and less so near the surface and near the canopy top. During the FFP periods for both fire experiments, median values for vertical to total heat flux and total momentum flux ratios were found to be lower than the median ratio values during the pre-FFP and post-FFP periods, with the differences being statistically significant $(p<0.001)$.

Cospectral analyses of the horizontal and vertical turbulent fluxes of heat and momentum during the fire experiments suggest that the passage of surface fire fronts in forested environments can substantially alter the heat and momentum flux cospectra that occur under typical non-fire-affected atmospheric surface-layer conditions, as reported in Kaimal et al. (1972). During FFP periods, cospectra power values increased across the entire frequency spectrum from their pre-FFP values, particularly for turbulent heat fluxes. The increases were prevalent at all heights within the forest overstory vegetation layers. Furthermore, the FFP cospectra power values in the inertial subrange may actually increase instead of decrease as the frequency of the flux variations increases. Slope values of the cospectral curves in the inertial subrange for the vertical fluxes of heat and momentum before, during, and after FFP departed substantially from the $-4 / 3$ value noted in Kaimal et al. (1972). During pre-FFP and postFFP periods, cospectra slope values in the inertial subrange approached $-2 / 3$ in most cases, while during FFP periods the inertial subrange slope values were sometimes close to 0 or even positive.

The cospectral analyses conducted in this study also revealed how surface wildland fires in forested environments can affect the temporal variability in horizontal and vertical turbulent fluxes of heat and momentum across a wide range of frequencies. The results suggest that while horizontal turbulent fluxes of heat and momentum may contribute more to the total turbulent heat and momentum fields than vertical turbulent fluxes in the vicinity of surface fires, the temporal variability in the vertical turbulent flux of heat can be enhanced to the extent that it exceeds the horizontal heat flux variability. The enhancement of the vertical heat flux variability compared to the horizontal heat flux variability was found to be most pronounced at the top of the canopy at frequencies less than $0.5 \mathrm{~s}^{-1}$ during FFP periods. The lower-intensity 2012 fire induced much stronger vertical than horizontal turbulent heat flux variations at the midcanopy level across the entire frequency spectrum during the post-FFP period, suggesting that some post-FFP environments may lead to highly variable vertical turbulent heat fluxes and/or weakly variable horizontal fluxes, particularly within canopy layers that may be present. Finally, the results suggest that surface wildland fires in forested environments may have less of an impact on turbulent momentum flux variability than on turbulent heat flux variability, regardless of height within the overstory vegetation layer or the frequency of variability.

The turbulent heat and momentum flux observations and their associated cospectra features presented in this wildland fire study point to the importance of accounting for multiscale interactions between fire, the atmosphere, and forest overstory vegetation when simulating or predicting the local effects of heat and momentum transfer on fuel heating, fire behavior, and smoke dispersion in forested environments. Further observational studies of atmospheric turbulence regimes in the vicinity of backing and heading line fires in forested environments coupled with concurrent high-frequency fire behavior measurements are needed to 1 ) assess how backing and heading fires differ in their potential effects on horizontal and vertical turbulent heat and momentum flux behavior and variability through the vertical extent of overstory vegetation, and 2) assess how those fluxes feed back onto fire behavior at different temporal and spatial scales. 
These types of wildland fire experiments should set the foundation for the development of improved predictive tools for local fuel heating, fire behavior, and smoke dispersion that properly account for fire-induced horizontal and vertical turbulent heat and momentum transfer in forested environments.

Acknowledgments. Funding for this study was provided by the U.S. Joint Fire Science Program under Project 09-1-04-1 and the U.S. National Fire Plan. We thank the anonymous reviewers of this paper for their constructive comments.

\section{REFERENCES}

Amiro, B. D., 1990: Drag coefficients and turbulence spectra within three boreal forest canopies. Bound.-Layer Meteor., 52, 227246, https://doi.org/10.1007/BF00122088.

Baldocchi, D. D., and T. P. Meyers, 1988: Turbulence structure in a deciduous forest. Bound.-Layer Meteor., 43, 345-364, https:// doi.org/10.1007/BF00121712.

Blanken, P. D., and Coauthors, 1998: Turbulent flux measurements above and below the overstory of a boreal aspen forest. Bound.-Layer Meteor., 89, 109-140, https://doi.org/10.1023/ A:1001557022310.

Byram, G. M., 1959: Combustion of forest fuels. Forest Fire: Control and Use, 1st ed. K. P. Davis, Ed., McGraw-Hill, 61-89.

Clements, C. B., and D. Seto, 2015: Observations of fireatmosphere interactions and near-surface heat transport on a slope. Bound.-Layer Meteor., 154, 409-426, https://doi.org/ 10.1007/s10546-014-9982-7.

— grass fires. Bull. Amer. Meteor. Soc., 88, 1369-1382, https:// doi.org/10.1175/BAMS-88-9-1369.

— S. Zhong, X. Bian, W. E. Heilman, and D. W. Byun, 2008: First observations of turbulence generated by grass fires. J. Geophys. Res., 113, D22102, https://doi.org/10.1029/ 2008JD010014.

— atmosphere interactions observed during low-intensity prescribed fires-RxCADRE 2012. Int. J. Wildland Fire, 25, 90-101, https:// doi.org/10.1071/WF14173.

Dupuy, J. L., and M. Larini, 1999: Fire spread through a porous forest fuel bed: A radiative and convective model including fire-induced flow effects. Int. J. Wildland Fire, 9, 155-172, https://doi.org/10.1071/WF00006.

Finney, M. A., and Coauthors, 2015: Role of buoyant flame dynamics in wildfire spread. Proc. Natl. Acad. Sci. USA, 112, 9833-9838, https://doi.org/10.1073/pnas.1504498112.

Frankman, D., and Coauthors, 2013: Measurements of convective and radiative heating in wildland fires. Int. J. Wildland Fire, 22, 157-167, https://doi.org/10.1071/WF11097.

Goodrick, S. L., G. L. Achtemeier, N. K. Larkin, Y. Liu, and T. M. Strand, 2013: Modelling smoke transport from wildland fires: A review. Int. J. Wildland Fire, 22, 83-94, https://doi.org/ 10.1071/WF11116.

Heilman, W. E., and Coauthors, 2013: Development of modeling tools for predicting smoke dispersion from low-intensity fires. U.S. Joint Fire Science Program Project 09-1-04-1 Final Rep., 64 pp., https://www.firescience.gov/projects/09-1-04-1/project/ 09-1-04-1_final_report.pdf.
—, C. B. Clements, D. Seto, X. Bian, K. L. Clark, N. S. Skowronski, and J. L. Hom, 2015: Observations of fire-induced turbulence regimes during low-intensity wildland fires in forested environments: Implications for smoke dispersion. At mos. Sci. Lett., 16, 453-460, https://doi.org/10.1002/asl.581.

$\longrightarrow$ X. Bian, K. L. Clark, N. S. Skowronski, J. L. Hom, and M. R. Gallagher, 2017: Atmospheric turbulence observations in the vicinity of surface fires in forested environments. J. Appl. Meteor. Climatol., 56, 3133-3150, https://doi.org/10.1175/ JAMC-D-17-0146.1.

Kaimal, J. C., J. C. Wyngaard, Y. Izumi, and O. R. Coté, 1972: Spectral characteristics of surface-layer turbulence. Quart. J. Roy. Meteor. Soc., 98, 563-589, https://doi.org/10.1002/ qj. 49709841707.

Katul, G., and Coauthors, 1999: Spatial variability of turbulent fluxes in the roughness sublayer of an even-aged pine forest. Bound.-Layer Meteor., 93, 1-28, https://doi.org/10.1023/ A:1002079602069.

Kiefer, M. T., and Coauthors, 2014: Multiscale simulation of a prescribed fire event in the New Jersey Pine Barrens using ARPS-CANOPY. J. Appl. Meteor. Climatol., 53, 793-812, https://doi.org/10.1175/JAMC-D-13-0131.1.

_ W. W. Heilman, S. Zhong, J. J. Charney, and X. Bian, 2015: Mean and turbulent flow downstream of a low-intensity fire: Influence of canopy and background atmospheric conditions. J. Appl. Meteor. Climatol., 54, 42-57, https://doi.org/10.1175/ JAMC-D-14-0058.1.

Kolmogorov, A. N., 1941: The local structure of turbulence in incompressible viscous fluid for very large Reynolds numbers. Dokl. Akad. Nauk SSSR, 30, 299-303.

Mandel, J., J. D. Beezley, J. L. Coen, and M. Kim, 2009: Data assimilation for wildland fires: Ensemble Kalman filters in coupled atmosphere-surface models. IEEE Contr. Syst. Mag., 29, 47-65.

Miranda, A. I., 2004: An integrated numerical system to estimate air quality effects of forest fires. Int. J. Wildland Fire, 13, 217226, https://doi.org/10.1071/WF02047.

Morandini, F., and X. Silvani, 2010: Experimental investigation of the physical mechanisms governing the spread of wildfires. Int. J. Wildland Fire, 19, 570-582, https://doi.org/10.1071/WF08113.

Moraes, O. L. L., D. R. Fitzjarrald, O. C. Acevedo, R. K. Sakai, M. J. Czilkowsky, and G. A. Degrazia, 2008: Comparing spectra and cospectra of turbulence over difference surface boundary conditions. Physica A, 387, 4927-4939, https://doi.org/10.1016/ j.physa.2008.04.007.

Morvan, D., and J. L. Dupuy, 2004: Modeling the propagation of a wildfire through a Mediterranean shrub using a multiphase formulation. Combust. Flame, 138, 199-210, https://doi.org/ 10.1016/j.combustflame.2004.05.001.

Nelson, R. M., B. W. Butler, and D. R. Weise, 2012: Entrainment regimes and flame characteristics of wildland fires. Int. J. Wildland Fire, 21, 127-140, https://doi.org/10.1071/WF10034.

Ottmar, R. D., and Coauthors, 2016: Measurements, datasets and preliminary results from the RxCADRE project-2008, 2011 and 2012. Int. J. Wildland Fire, 25, 1-9, https://doi.org/10.1071/WF14161.

Patton, E. G., P. P. Sullivan, and K. J. Davis, 2003: The influence of a forest canopy on top-down and bottom-up diffusion in the planetary boundary layer. Quart. J. Roy. Meteor. Soc., 129, 1415-1434, https://doi.org/10.1256/qj.01.175.

Pimont, F., J. L. Dupuy, R. R. Linn, and S. Dupont, 2009: Validation of FIRETEC wind-flows over a canopy and a fuel-break. Int. J. Wildland Fire, 18, 775-790, https://doi.org/10.1071/WF07130.

Potter, B. E., 2002: A dynamics based view of atmosphere-fire interactions. Int. J. Wildland Fire, 11, 247-255, https://doi.org/ 10.1071/WF02008. 
Press, W. H., and G. B. Rybicki, 1989: Fast algorithm for spectral analysis of unevenly sampled data. Astrophys. J., 338, 277-280, https://doi.org/10.1086/167197.

Raupach, M. R., J. J. Finnigan, and Y. Brunet, 1996: Coherent eddies and turbulence in vegetation canopies: The mixing layer analogy. Bound.-Layer Meteor., 78, 351-382, https://doi.org/ 10.1007/BF00120941.

Scargle, J. D., 1982: Studies in astronomical time series: IIStatistical aspects of spectral analysis of unevenly spaced data. Astrophys. J., 263, 835-853, https://doi.org/10.1086/160554.

Seto, D., and C. B. Clements, 2011: Fire whirl evolution observed during a valley wind-sea breeze reversal. J. Combust., 2011, https://doi.org/10.1155/2011/569475.

, $\longrightarrow$, and W. E. Heilman, 2013: Turbulence spectra measured during fire front passage. Agric. For. Meteor., 169, 195-210, https://doi.org/10.1016/j.agrformet.2012.09.015.

, T. M. Strand, C. B. Clements, H. Thistle, and R. Mickler, 2014: Wind and plume thermodynamic structures during low- intensity subcanopy fires. Agric. For. Meteor., 198-199, 53-61, https://doi.org/10.1016/j.agrformet.2014.07.006.

Shaw, R. H., R. H. Silversides, and G. W. Thurtell, 1974: Some observations of turbulence and turbulent transport within and above plant canopies. Bound.-Layer Meteor., 5, 429-449, https://doi.org/10.1007/BF00123490.

Simpson, C. C., J. J. Sharples, and J. P. Evans, 2016: Sensitivity of atypical lateral fire spread to wind and slope. Geophys. Res. Lett., 43, 1744-1751, https://doi.org/10.1002/2015GL067343.

Stull, R. B., 1988: An Introduction to Boundary Layer Meteorology. Kluwer Academic, 666 pp.

Sun, R., S. K. Krueger, M. A. Jenkins, M. A. Zulauf, and J. J. Charney, 2009: The importance of fire-atmosphere coupling and boundary-layer turbulence to wildfire spread. Int. J. Wildland Fire, 18, 50-60, https://doi.org/10.1071/WF07072.

Wilczak, J. M., S. P. Oncley, and S. A. Stage, 2001: Sonic anemometer tilt correction algorithms. Bound.-Layer Meteor., 99, 127-150, https://doi.org/10.1023/A:1018966204465. 